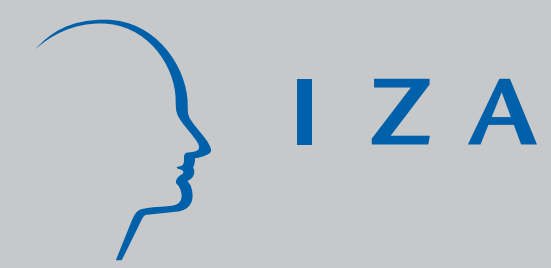

IZA DP No. 1191

Other-Regarding Preferences and Performance

Pay - An Experiment on Incentives and Sorting

Tor Eriksson

Marie-Claire Villeval

J une 2004 


\title{
Other-Regarding Preferences and Performance Pay - An Experiment on Incentives and Sorting
}

\author{
Tor Eriksson \\ Aarhus School of Business \\ Marie-Claire Villeval \\ GATE, CNRS, \\ University of Lyon 2 and IZA Bonn \\ Discussion Paper No. 1191 \\ June 2004
}

IZA
P.O. Box 7240
53072 Bonn
Germany

Phone: +49-228-3894-0

Fax: +49-228-3894-180

Email: iza@iza.org

Any opinions expressed here are those of the author(s) and not those of the institute. Research disseminated by IZA may include views on policy, but the institute itself takes no institutional policy positions.

The Institute for the Study of Labor (IZA) in Bonn is a local and virtual international research center and a place of communication between science, politics and business. IZA is an independent nonprofit company supported by Deutsche Post World Net. The center is associated with the University of Bonn and offers a stimulating research environment through its research networks, research support, and visitors and doctoral programs. IZA engages in (i) original and internationally competitive research in all fields of labor economics, (ii) development of policy concepts, and (iii) dissemination of research results and concepts to the interested public.

IZA Discussion Papers often represent preliminary work and are circulated to encourage discussion. Citation of such a paper should account for its provisional character. A revised version may be available on the IZA website (www.iza.org) or directly from the author. 


\title{
ABSTRACT
}

\section{Other-Regarding Preferences and Performance Pay - An Experiment on Incentives and Sorting}

\begin{abstract}
Variable pay not only creates a link between pay and performance but may also help firms in attracting the more productive employees (Lazear 1986, 2000). However, due to lack of natural data, empirical analyses of the relative importance of the selection and incentive effects of pay schemes are so far thin on the ground. In addition, these effects may be influenced by the nature of the relationship between the firm and its employees. This paper reports results of a laboratory experiment that analyzes the influence of other-regarding preferences on sorting and incentives. Experimental evidence shows that (i) the opportunity to switch to piece-rate increases the average level of output and its variance; (ii) there is a concentration of high skill workers in performance pay firms; (iii) however, in repeated interactions, efficiency wages coupled with reciprocity and inequality aversion reduce the attraction of performance related pay. Other-regarding preferences influence both the provision of incentives and their sorting effect.
\end{abstract}

JEL Classification: $\quad$ M52, J33, J31, C81, C91

Keywords: performance pay, incentives, sorting, selection, other-regarding preferences, experiment

Corresponding author:

Marie-Claire Villeval

GATE

93, chemin des Mouilles

69130 Ecully

France

Email:villeval@gate.cnrs.fr 


\section{Introduction}

In the last two decades the prevalence of different forms of variable pay has increased substantially in many firms and many countries. Variable pay schemes are typically motivated by the incentive effect they exert on the employees by linking pay to performance. It is, however, frequently forgotten that performance related pay may also help firms in attracting the most productive employees and to weed out the less productive ones. If this sorting effect is not accounted for, the higher efficiency observed when comparing a piece-rate compensation scheme relative to an hourly wage scheme may be unduly attributed to the incentive effect of the variable wage (Lazear, 1999). The sorting effect arises for two reasons. The highly productive employees will prefer performance pay to hourly or monthly pay in as much as they know that their productivity is higher than that of the other employees in the firm. Thus, performance pay enables them to increase their income from work. In contrast, the less productive employees will tend to quit or avoid joining firms that use performance pay schemes, because they are not attractive to them. In all likelihood, both the incentive and the sorting effects coexist in many organizations.

A first aim of this paper is to report the results of a laboratory experiment designed to measure the incentive and the sorting effects of performance-pay. This is motivated by the fact that the productivity enhancing effect of performance has been called in question in the literature and that due to the scarcity of natural data, empirical analyses of the selection effect, its role and magnitude, have been thin on the ground.

As regards the incentive effect of performance pay, one strand of the literature emphasizes the repetitive game nature of employment contracts (see Malcolmson 1999, 
for a survey) and argues that the adoption of incentive pay depends on labor market conditions (MacLeod and Malcomson 1989, 1999) or competition in the product market (Bertrand forthcoming). Confirming the incentive effect of piece-rates, others have stressed that the alternative efficiency wages should lead to an increase in unit costs to produce the same incentive effect than piece-rates (Shearer 2004). Baker et al. (1994) show that implicit or relational contracts may reinforce or crowd out explicit incentive contracts. Bohnet and Oberholzer-Gee (2002) argue that in some cases the selection effect counteracts the motivational effect of rewards.

So far, the identification of a sorting effect of performance pay distinct from its incentive effect has been hampered by the lack of natural data. The best way to isolate the two effects is to use personnel files of firms that have changed their compensation schemes. This has been done in a widely cited econometric case-study of the Safelite Company by (Lazear, 1999, 2000). Barro and Beaulieu (2003) study a large hospital company which switched from salary to profit sharing plan compensation and find also both increases in output and selection effects. But otherwise evidence is scarce. ${ }^{1}$ Following the strategy in Lazear (2000) is in most cases difficult as the switch from one compensation scheme to another cannot be considered as exogenous and finding good instruments for the choice of compensation scheme is extremely difficult. ${ }^{2}$ Parent (1997) estimates a fixed effects model on individual data from the NLSY, and shows

\footnotetext{
1 Other studies focus more on incentive effects. Freeman and Kleiner (1998) study the impact of introducing piece rates in a shoe manufacture and find that piece rates increased productivity but lowered overall performance. From a field experiment conducted in a tree-planting company, Paarsch and Shearer (1999) estimate the behavioral parameters describing the employees' reactions to a change in the compensation system from a structural model. Similarly, Shearer (2004) finds that pay for performance increases productivity by more than $20 \%$. Nagin et. al. (2002) examine piece rates in a call center and find them to be very effective. They stress the importance of measuring output appropriately in order to obtain the gains.

2 Another problem is finding data on individual performance under both fixed wage and variable schemes.
} 
that the effect of piece-rate on pay is associated with an incentive effect, whereas the effect of bonuses is more related to a sorting effect. A limitation is that the data do not inform about the proportion of the wage that is variable. Booth and Frank (1999) make use of panel data on individuals to control for both observable worker characteristics and unobservable heterogeneity. However, no direct measure of productivity is available. Experimental methods may help in circumventing some of these difficulties, notably in guaranteeing the exogeneity of the introduction of performance-pay.

The laboratory experiment, the results of which are reported in this paper, has been designed to test the following key predictions derived from Lazear's (2000) model: (i) a switch from a fixed to a variable wage increases the average level of output per worker, (ii) introducing the possibility for the employees (and consequently also for the firms) of moving to a variable wage increases the variance in output, (iii) the gain in productivity is due to both an incentive effect and a sorting effect, and (iv) the introduction of performance-pay in some firms leads to a segmentation of the labor market with high skill employees concentrated in the performance-pay firms and the low skill employees populating the fixed-pay firms. The experimental methodology employed in the current paper offers an opportunity to examine the respective roles of these incentive and sorting effects when both a fixed wage and a variable reward system become available to the employees. It both allows to strictly control the environment (skill levels, structure of pay) and provides precise measures of the agents' productivity and mobility.

A second aim of the experiment is to examine the influence of other-regarding preferences, such as fairness and reciprocity, on the incentive and sorting effects of pay schemes. In practice, employment relationships are usually designed as long term 
relationships. We have learned from many experiments (Falk, Gächter and Kovacs, 1999, Fehr, Gächter and Kirchsteiger, 1997, Fehr, Kirchsteiger and Riedl, 1998) that in finitely repeated games where reputation building may occur, the interaction of reciprocally motivated subjects and selfish subjects may lead to the enforcement of labor contracts even in the absence of a formal incentive system. In such a context, the introduction of explicit incentives may even crowd out voluntary cooperation (Fehr and Gächter, 2002). Thus, we could also hypothesize that repeated game informal incentives such as fairness and reciprocity may have an impact on both the incentive and the sorting effects of the pay schemes in long-term employment relationships. In particular, one can ask whether the generosity of a fixed wage can have the same incentive effect as a variable pay scheme and attract the same kind of employees. For example, a fair employer may be willing to offer a high fixed wage which sorts employees according to their degree of reciprocity rather than according to their skill level. More specifically, we test the additional hypotheses that: $(v)$ the effect on output of the availability of variable pay is affected by the nature of the employment relationship, and that (vi) the sorting effect on skills of the contractual choice is weakened in a repeated interaction due to the action of social motivations.

To test these hypotheses, our experiment involves firms and workers with two possible skill levels who have an opportunity to contract and work under different pay schemes. It consists of two conditions, a "posted bid market" condition and a "partner matching" condition, which correspond to a spot labor market and a long-term employment relationship respectively, and two treatments, a "fixed wage" treatment and a "menu" treatment. Under the posted bid market condition, we first implement an exogenous fixed wage treatment. Each firm designs a contractual offer consisting of a fixed wage 
level and a desired level of effort that is posted on the market. Each employee can then successively choose an employment contract and decide on their actual level of effort.

Next we implement the menu treatment in which the firms offer a menu of contracts including both a variable pay scheme in which the wage increases in the level of effort according to a price schedule exogenously imposed on all firms and a fixed pay scheme.. Unlike in (Fehr and Schmidt, 2000), where principals choose between an explicit contract and an implicit contract, in our experiment the choice between the fixed and the variable pay schemes is made by the employees before they choose their effort level. Under the partner matching condition, a firm and a worker are paired throughout the session. The subjects are first submitted to the fixed wage treatment and then to the menu treatment. This design enables us to analyze whether the presence of motivations such as fairness and reciprocity affects the design of pay schemes and their incentive and sorting effects.

Our findings support the six hypotheses mentioned above. Under the market condition, most employees do not reciprocate to the firms' fairness as expressed by the offer of non-minimum fixed wages and they move rapidly towards the minimum wage minimum effort equilibrium. When a variable pay scheme becomes available, the average output of workers as well as its variance increases substantially. The increase arises mainly because the high skill employees select the variable pay scheme as they can improve their payoff under such wage conditions by exerting a higher effort. As a consequence, the labor market becomes highly segmented with the low skill employees remaining in fixed pay firms, whilst most high skill employees are working under a variable pay scheme and producing high output. In the repeated interaction game, however, and relatively to the market protocol, most firms offer higher fixed wages, 
workers perform a higher average level of output under the fixed pay scheme and the high skill employees are less inclined to switch to a variable pay scheme. Thus, otherregarding preferences affect contractual choices and the sorting effect of performance pay schemes. This suggests that efficiency wages may be a reason for why firms do not adopt variable pay schemes and they favor a sorting effect more in terms of employees’ degree of reciprocity than in terms of skill level.

In Section 2, we present the theory behind the incentive and sorting effects we attempt to identify. In Section 3, the experimental design and the experimental procedures are outlined. The empirical results are presented in Section 4. Section 5 summarizes and concludes.

\section{The Model}

In this section, we present a simple model that emanates from Lazear (2000). Denote by $S$ the skill of the employee and by $e$ her level of effort. The observable output is $y$, with $y_{0}$ the minimum level of output below which the employee is fired. Then production is:

$$
y=f(e, S)
$$

with $f^{\prime}>0$ and $f^{\prime \prime}>0$

The utility of the employee is given by:

$$
U(w, e)
$$

where $w$ denotes the wage level and with $U^{\prime}>0$ and $U^{\prime \prime}<0$

For any given level of output $y$, there is a unique effort level that satisfies (1). In addition, $e_{0}(S)$ is the level of effort necessary to produce:

$$
y_{0}=f\left(e_{0}(S), S\right)
$$


given $\frac{\delta e}{\delta S}=-\frac{f^{\prime}}{f^{\prime \prime}}<0$ (that is, a high ability employee needs less effort to achieve the same output than a low ability worker). Each employee compares the rent she can earn in different firms. Let $U(\hat{w}(S), \hat{e}(S))$ be her utility in her best alternative. The employee is indifferent between the two alternatives when $U\left(w, e_{0}(S)\right)=U(\hat{w}(S), \hat{e}(S))$.

Consider now the switch from a fixed wage to variable wage. In the variable pay scheme, the linear piece rate wage is given by $(b y-K)$, where $K$ could be interpreted as a monitoring or a measurement cost imposed on the employee. Thus, the utility of an employee under the variable pay scheme now becomes:

$$
\left.U_{P R C}=U\left(b f\left(e^{*}(S), S\right)-K, e^{*}(S)\right)\right)
$$

where $e^{*}(S)$ is the effort level corresponding to the offer of $b$.

If the firm switching from a fixed to a variable pay scheme decides to guarantee a minimum wage corresponding to the previous wage with $e=e_{0}$, then in equilibrium the employees, who would have received less than the minimum wage under the variable pay scheme, receives $w$ as a guarantee after the switch, and consequently stay in the same firm. The wage of an employee is then given by:

$$
w=\max (w, b y-K)
$$

i.e., the employee receives $w$ if $y_{0} \leq y \leq y^{*}$ and (by-K) if $y>y^{*}$.

If the firm switching from a fixed to a variable pay scheme decides not to guarantee a minimum wage corresponding to the previous wage, all employees receive (by-K). Compared to the previous fixed wage, the employees with a low ability will suffer a 
relative loss and will be inclined to quit. If the previous wage is guaranteed by a variable pay firm, a low skill employee will be indifferent between staying and moving. In any case, a high skill employee will be better off in a variable- than in a fixed wage firm and she should move from a fixed to a variable pay firm. The following figure (from Lazear 2000) describes the effort decisions:

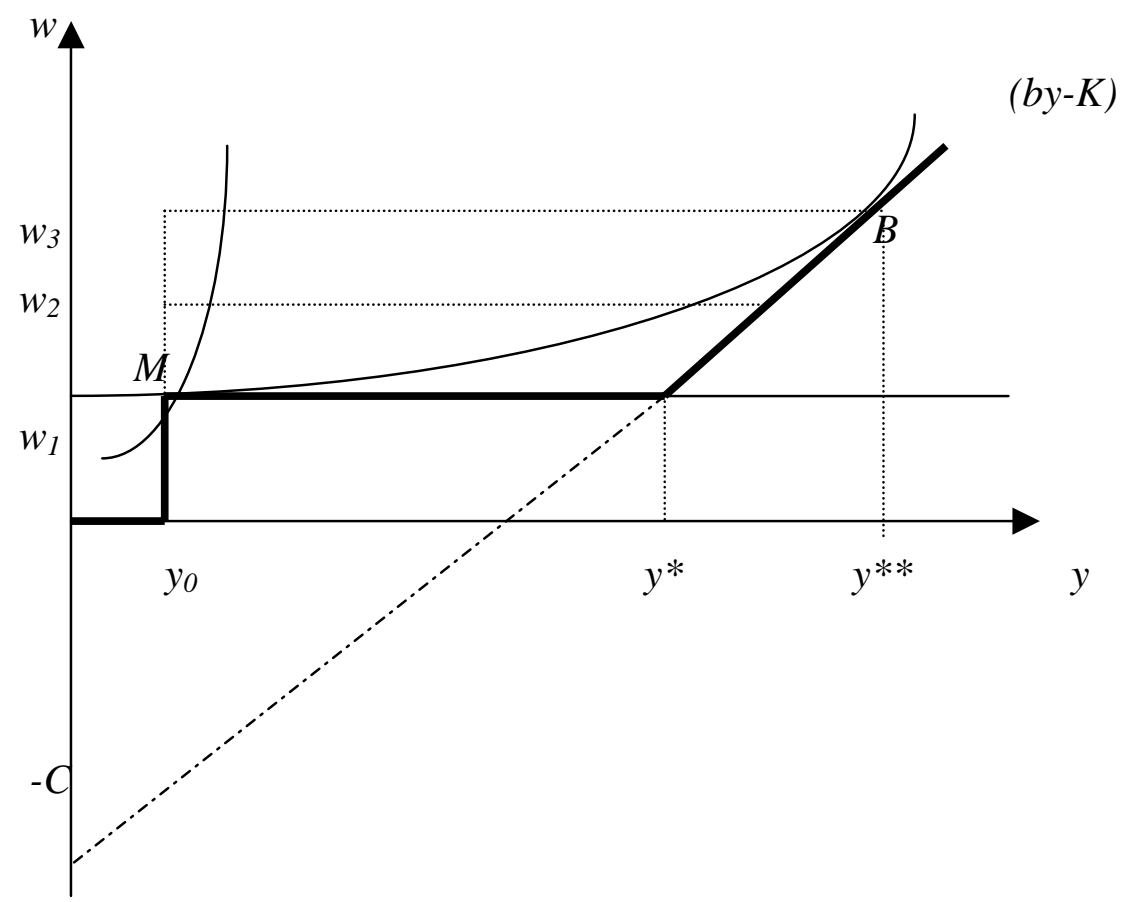

Figure 1. Efforts under fixed and variable pay schemes

The indifference curve is steeper for the low skill employee. Hence, under both the fixed and the variable pay schemes, the low skill employee will produce $y=M$. Under the fixed pay scheme, the high skill agent will produce the minimum requirement $y=M$ but under the variable pay scheme, she will earn more if producing $y^{* *}=B$. Thus, the average production increases after the switch but also the variance of the employees' output. The increase in output is due both to the incentive effect on the high skill employees and to the sorting effect. If there is no guarantee after the switch, then all employees producing less than $y^{*}$ should leave the firm for another firm using a fixed pay scheme. No employee should produce between $y_{0}$ and $y^{* *}$. 
How are these predictions influenced by the absolute level of the fixed wage? As shown by Figure 1, increasing the fixed wage $w_{1}$ to $w_{2}$ gives rise to the same segmentation but at a higher cost for the firm. As the fixed wage reaches $w_{3}$, the skill employee is better off choosing the fixed wage and the minimum effort. Thus, under the assumption of selfishness, it is not rational for a firm to choose a fixed wage higher than $w_{1}$.

\section{The Experimental Design}

After a presentation of the experimental protocol, we will derive the theoretical predictions. Thereafter, the experimental procedure will be developed.

\section{A. The protocol}

In our experiment, there are two main categories of participants: the firms and the employees ${ }^{3}$, in equal number. ${ }^{4}$ There are two types of employees, the low skill type and the high skill type in equal number and this distribution is common knowledge among all the participants. These two types of employees differ with respect to their convex cost functions which are also common knowledge: for performing the same level of effort, the low skill employee has to bear a higher cost than the high skill employee (see Table 1). The level and the cost of effort are denoted by $e$ and $c(e)$, respectively.

Table 1. Effort levels and costs of effort by type of agents

\footnotetext{
${ }^{3}$ A more general wording was used during the experiment that was phrased in terms of "buyers - sellers". "X"- and "Y- sellers" designated the low and high skill employees, respectively. Price and quality were used instead of wage and effort. Indeed, contextualizing the experiment is likely to generate biases since the denomination of high- or low- skill employees could have introduced a stigma effect among the participants and because the duration of the employment relationship is known to have an influence on behavior. The instructions are described in Appendix.

${ }^{4}$ We have not imposed a shortage in the labor market for three main reasons. We are not primarily interested in the role of competition on the effect of pay scheme on productivity. It would have increased the imbalance in payoffs according to the role of the participants, since in some periods some agents would have been "unemployed". It would have induced the employee-participants to hasten their decision making, increasing the risk of "mistakes". In our experiment voluntary unemployment arises only when an employee rejects a contract offer (which can always generate a positive payoff).
} 


\begin{tabular}{lccccc}
\hline Effort $e$ & 0.2 & 0.4 & 0.6 & 0.8 & 1 \\
\hline Low skill employee $c_{L}(e)$ & 2 & 6 & 12 & 20 & 30 \\
High skill employee $c_{H}(e)$ & 1 & 3 & 5 & 8 & 12 \\
\hline
\end{tabular}

Each experimental session consists of two parts corresponding to two different treatments, the so-called Fixed Wage Treatment and Menu Treatment. All the participants have been subjected to both treatments. The experiment has been conducted under two conditions: a posted bid market condition and a partner matching condition.

Consider first the posted bid market condition. In the first part of 3 sessions, we implement the Fixed Wage Treatment. Each trading period includes two stages. The first stage of each period is a posted bid market. Each firm posts an incomplete labor contract to the market: it chooses both the amount of the fixed wage it offers, $w$, under the constraint of an exogenous minimum wage the amount of which is 20 , and a nonbinding desired level of effort, $\hat{e}$. Compared with the standard gift-exchange game introduced by Fehr, Kirchsteiger and Riedl (1993), the possible values of wages and effort are for the sake of simplicity less numerous but the theoretical predictions remain the same. The wage can take four possible values, $w \in(20,25,35,45)$. The desired effort level is among the values $(0.2,0.4,0.6,0.8$ and 1$)$. During a period, each firm cannot revise its offer, is not allowed to offer more than one contract, and cannot make an offer to a specific employee, each employee being allowed to accept any offer whatever her skill level. All the contractual offers are displayed simultaneously on every employee’s screen. As in (Fehr, Kirchsteiger and Riedl, 1996) a random mechanism determines the order in which each employee can choose among the remaining available contracts. The choice of a contract is not guided by the speed of 
decision-making; this reduces the influence of stress on decision-making. An employee can choose only one contract and she can reject all offers.

In the second stage, the employee who has accepted a contract immediately chooses her actual effort level from the set of feasible levels. The firm is informed about the acceptance of its offer by an employee, the skill level of this employee and her choice of effort. Only the firm is informed about the type of its own employee and about her effort choice. Effort is perfectly verifiable but no fine can be imposed on the employee who cheats on the desired level of effort. Each participant is informed about her payoff in the current period. The payoffs for one period are calculated as follows:

- for the employee:

$\pi^{E}=w-c(e)-8 \quad$ (with 8 being a fixed cost of effort) upon acceptance of a contract, and = 0 otherwise;

- for the firm:

$\pi^{F}=(v-w) e$ upon acceptance of its offer, and $=0$ otherwise, where $v$ denotes a redemption value, i.e. the gross profitability of each unit of effort chosen by the employee. In this experiment, $v=100$. Like in (Fehr, Kirchsteiger and Riedl, 1993, 1998, Gächter and Falk, 2002), this guarantees that the firm can make no loss, avoiding disturbances in the data due to loss aversion phenomena.

Next a new period starts automatically. Since contracts apply for a single period, the launching of a new period reopens the market. It is therefore impossible for a firm to reward or to punish the past decision of a specific employee since identities of the trading partners are unknown. This rules out reputation formation. The first part of the experiment consists of 8 trading periods, the number of which is common knowledge. 
In the second part of these sessions, we implement the Menu Treatment. Now, two pay schemes may coexist in the market. In the first stage of each period, the firm posts a menu of contracts to the bid market. The menu includes both an exogenously defined variable pay contract and a fixed pay contract. ${ }^{5}$ The variable pay contract states that the wage can take four possible values, $w \in(20,25,35,45)$ and that the actual wage level paid to the employee will depend on the actual level of effort chosen by this employee in the second stage of the period, according to the following relationship:

$$
w=\operatorname{Max}(20, b(e)-K)
$$

where $b$ is arbitrarily fixed at 50 and $K$ at 5 and 20 is the exogenously given minimum wage. ${ }^{6}$ The fixed pay contract is an incomplete contract, which specifies both a wage and a desired level of effort exactly like in the first treatment. The wage can still take four possible values, $w \in(20,25,35,45)$. Unlike the fixed pay scheme in which the wage is paid before the choice of the effort, under the variable pay scheme the wage is paid after the choice of effort by the employee.

The variable pay scheme incorporates a minimum wage guarantee that is common to all firms. To avoid any distortion this minimum wage is the same as in the fixed pay scheme. We could also consider that the fixed wage offered in the menu of contracts constitutes a firm's specific wage guarantee. Each employee has not only to choose one firm, but also one contract with either a fixed or a variable pay scheme.

\footnotetext{
${ }^{5}$ This design guarantees that the participants will not face a shortage of variable pay contract offers. The choice of a contract will not be affected by its availability. These two pay schemes were termed two "modes of payment", with "mode A" as the fixed pay scheme and "mode B" as the variable pay scheme. The latter was presented as a "price schedule" common to all buyers.

${ }^{6}$ For simplicity and because we are chiefly interested in the contractual choice by the employee, we decided not to have a protocol in which each firm would determine its value for $b$.
} 
In the second stage of each period, the employee decides on her actual effort level, given the payment scheme she selected from the menu of contracts. All the other conditions introduced in the first treatment continue to apply. At the end of this stage, the firm is informed about the acceptance of its offer, the type of its employee, and the employee's choice of both pay scheme and actual effort level. Each participant is informed about her payoff in the current period.

This design implies that in the second part of these sessions, which also consists of 8 trading periods, we should observe both types of compensation rules in the market. It enables us to analyze for each type of employee the attraction of each pay scheme, the impact of the pay scheme and the amount of pay on the effort levels.

To control for the possibility of an order and a learning effects on individual decisions, we also conducted three sessions under the market condition with the Menu Treatment implemented in the first 8 periods and the Fixed Wage Treatment in the further 8 periods.

Consider now the partner matching condition that was implemented in three other sessions. At the beginning of the session, firms and employees were matched to form pairs that remained intact throughout the session. Before making its first decision, the firm was informed about the skill level of its employee. The first part of these sessions consisted of the Fixed Wage Treatment and the second part of the Menu Treatment. In the first stage of each period in the first part, the firm makes an offer to its own employee consisting of a wage and a desired level of effort. The employee then decides on whether to accept or to reject this offer. In case of a rejection, both earn nothing. In case of an acceptance, in the second stage, the employee chooses her actual level of effort. Under the Menu Treatment, the firm makes an offer which includes a variable 
pay scheme and a fixed pay scheme associated with a desired level of effort. The employee may either accept or reject this menu of contracts. If she accepts, she chooses the payment scheme together with her actual level of effort. The payoff functions and feedback information are the same as in the other condition.

\section{B. Theoretical predictions}

Under the assumption of rationality and selfishness, the predictions of the game are straightforward. In the posted bid market condition, under the Fixed Wage Treatment, at the second stage, whatever her type and irrespective of the wage contracted upon, any employee should provide $e^{*}=e_{\min }=0.2$. No employee has an incentive to choose a higher level of effort since her cost increases in the effort level and because she can be neither punished nor rewarded for her actual effort. The firm should, therefore, offer the contract (fixed wage $w^{*}=20$ and $\tilde{e}=0.2$ ) with the minimum wage in the first stage. This offer should be accepted by any employee since a rejection can provide her with no better alternative. This prediction would not change if the firm was informed in advance about the type of the employee it contracted with. The firm's payoff, given by $(v-w) * e$, should thus amount to 16 , while the high and low skill employees should earn $11\left(w_{\text {min }^{-}}\right.$ $\left.c\left(e_{\min }\right)-8\right)$ and 10, respectively.

Should the employees opt for a variable pay scheme when the opportunity of choice is available, i.e. in the Menu Treatment? Let us consider the high skill employee first. Choosing the variable pay scheme enables her to receive a high wage (45), provided she performs the maximum effort level $\left(e_{H V}{ }^{*}=1\right)$, which enables her to reach his highest utility (25). She is better off than choosing the fixed pay scheme which makes her earn 11 in equilibrium in exchange for a wage of 20 and the minimum effort level 
$\left(e_{H F}{ }^{*}=0.2\right)$. The variable pay scheme should thus attract the high skill employees, who are able to increase their payoffs by choosing the maximum effort. In contrast, the low skill employee should provide the minimum effort under both schemes $\left(e_{L V}{ }^{*}=e_{L F}{ }^{*}=0.2\right)$ as she earns 10 irrespective of which pay scheme is chosen and should thus be indifferent between the two. As a consequence, the firm should offer the menu of contracts (variable pay scheme; fixed pay scheme with $w^{*}=20$ and $\tilde{e}=0.2$ ) which is (imperfectly) separating ${ }^{7}$. The firm is better off under the Menu Treatment than under the Fixed Wage Treatment, because it can attract a high skill employee, who should opt for the variable pay scheme, choose the maximum effort and be compensated by the maximum wage. In the latter case, the payoff to the firm amounts to $(v-b(e)+K) * e=55$. If it recruits a low skill employee, it will compensate her with the minimum wage and whatever the mode of payment chosen by this employee, the firm's payoff will amount to only 16 . Since the firm does not know which type of employee will accept its offer in the posted bid market condition, its expected payoff is 35.5 in the Menu Treatment, to be compared with the certain payoff of 16 received under the Fixed Wage Treatment.

Under the partner matching condition, since the game is repeated finitely, predictions regarding the decisions of both the firm and the employees are similar except that the firm knows the type of its employee. Under the Menu Treatment, the firm’s equilibrium payoff is therefore 55 when it is matched with a high skill employee and 16 when matched with a low skill employee.

\footnotetext{
${ }^{7}$ This menu of contracts is imperfectly separating since the low skill employee is indifferent between the two pay schemes due to the minimum wage guarantee. Note also that in the market protocol, there are no strategic interactions among firms. The firms do not know the prices offered by the other firms, the employees choose successively according to a random order and the variable pay scheme is common to all firms and available in all of them. Therefore, the firm cannot try to attract a skill employee instead of its competitors by increasing its fixed wage offer.
} 
Thus, if all participants have purely selfish preferences, we should when moving from a Fixed Wage Treatment to a Menu Treatment observe (a) an increase in the average individual effort, (b) an increase in the variance of effort, (c) and a sorting of the employees according to their type, with the high skill employees concentrated in the variable pay scheme and the low skill employees in the fixed pay scheme due to the offer of a (imperfectly) separating menu of contracts.

However, we know from many experimental studies of the labor market (Fehr, Kirchsteiger and Riedl, 1993, 1998, Fehr and Schmidt, 1999, Gächter and Falk, 2002) that individual behavior may also be shaped by other-regarding preferences such as fairness, reciprocity and inequality aversion. We now turn to consider what would happen if the firm is fair and expects the employees to be reciprocal in the posted bid market condition. Under the Fixed Wage Treatment, the firm may deviate by offering $w=45$ and asking $\tilde{e}=0.6$ if expecting a reciprocal and inequality averse employee. If the employee is reciprocal and chooses an actual effort equal to the desired one, the firm would earn 33, a high skill employee 32 and a low skill employee 25. All players should be better off with this fairness strategy compared with the equilibrium based on selfish assumptions. This strategy is not very risky for the firm since it increases its expected profit more in case the agents are reciprocal (it earns 33 instead of 16) than it decreases it if they turn out to be selfish and choose the minimum effort (it earns 11 instead of 16). Under the Menu Treatment, a fair and inequality averse firm may offer the menu of contracts (variable pay scheme; fixed pay with $w=45$ and $\tilde{e}=0.6$ ), which is not separating. Its expected payoff is still 33 if the employee is reciprocal and inequality averse whatever her skill level. Both employees should choose a fixed pay scheme which may both increase their payoffs and reduce the difference in payoffs relative to 
the firm as compared with the variable pay scheme. Unlike in the Fixed Wage Treatment, in making such a generous offer the firm is making a sacrifice if it is matched with a high skill employee, since it could earn more if this employee chooses the variable wage and the high level of effort. This strategy is, however, more risky than under the Fixed Wage Treatment since in the case that the offer is accepted by a selfish employee the latter will opt for the fixed pay scheme and make the minimum effort leaving the firm with a payoff of 11 . Had the firm offered a fixed wage of 20 , the high skill employee would have been better off by opting for the variable pay and choosing the maximum effort, thus guaranteeing the firm a 55 payoff. But fairness and positive inequality aversion may motivate generous offers.

Consequently, accounting for other-regarding preferences from both sides, we should, when moving from a Fixed Wage to a Menu Treatment, observe ( $\left.a^{\prime}\right)$ a smaller increase in the average individual effort than under the assumption of selfishness, and ( $b$ ') less sorting of the employees, more of both types being concentrated in the fixed pay scheme. Under the partner matching condition, where the firm knows the type of its employee, the same predictions can be made. The fair strategy is less risky since the firm can punish a selfish employee by offering a low wage in the subsequent periods. Similarly, an employee can punish a selfish firm by rejecting its offer.

\section{The procedures}

The experiment consisted of 9 sessions, with each session comprising two parts of 8 periods each. Six sessions were conducted under the posted bid market condition. In half of them, participants were first subjected to the Fixed Wage Treatment and then to 
the Menu Treatment; the other half was conducted in the reverse order. ${ }^{8}$ This gives a total of 760 observations $^{9}$. In the 3 other sessions we implemented the partner matching protocol, with the Fixed Wage Treatment imposed before the Menu Treatment. This yields 384 additional observations. These sessions were conducted in the GATE (Groupe d'Analyse et de Theorie Economique) laboratory, Lyon. The 144 participants were recruited from various undergraduate courses in the area's Textile Engineering School, Ecole Centrale Engineering School, Lyon School of Management and faculty of economics (18\% of the subjects were economics students but not trained in game theory or labor economics). No subject participated in more than one session. The experiment was computerized using the Regate software (Zeiliger, 2000).

Participants were randomly assigned to a specific computer terminal, depending on the computer name drawn randomly from a box upon entering the room. Before the decision-making began, written instructions for the first part of the experiment were distributed to participants and read aloud by the experimenter (see Appendix). Questions were answered privately by the experimenter. In addition, to make sure that the participants understood the rules of the game, they had to answer a questionnaire including a series of questions about the computation of firms’ and employees’ payoffs. When all participants had answered the questions correctly, the experiment started. No communication was allowed.

Each participant then observed on his or her computer screen the role he or she was assigned to play. Since 16 subjects participated in each session, 8 of them were allocated the role of a firm, 4 the role of a low skill employee and 4 the role of a high

\footnotetext{
${ }^{8}$ In the econometric analyses we carried out, it turned out that the order did not affect the results obtained.
} 
skill employee. Role assignments remained unchanged throughout the entire session. All interactions were anonymous and the subjects were never informed about the identity of the participants they interacted with in any of the periods. After the completion of the first part, the instructions for the second part of the experiment were distributed and read aloud. The participants were given time to read these new instructions. When the second part consisted of the Menu Treatment, they had to answer a small questionnaire checking whether they were able to read the new tables but the individual corrections were silent and no questions were allowed.

Each session lasted on average 90 minutes, excluding payment of participants. All amounts were given in points, with conversion into Euros at a rate of 100 points $=€ 4$ upon completion of the session. At the end of the session, the participants were asked to enter one by one into a separate room to be paid in private with cash. Payment consisted of the sum of payoffs during each period plus a $€ 4$ show-up bonus. On average in the posted bid market condition, the firms earned $€ 18$ (standard deviation: $€ 3$ ), the low skill employees $€ 14$ (st.dev.: $€ 2$ ) and the high skill employees $€ 16$ (st.dev.: $€ 2$ ). On average in the partner matching condition, the firms earned $€ 19$ (standard deviation: $€ 6$ ), the low skill employees $€ 15$ (st.dev.: €4) and the high skill employees $€ 18$ (st.dev.: $€ 4$ ).

\section{Experimental Results}

\section{A. The incentive effect and the sorting effect of variable pay}

With selfish preferences, the model predicts that after a switch from a fixed pay to a variable pay scheme (i) the average individual effort increases, and (ii) the variance of effort increases. Our experimental data show that the average individual effort is 0.28

\footnotetext{
${ }^{9}$ Among these 760 observations, 384 have been collected under the Fixed Wage Treatment and 376 under the Menu Treatment. Due to a technical breakdown, we lost the 8 observations from one period in one
} 
under the Fixed Wage Treatment and it rises to 0.47 under the Menu Treatment (+ $67.9 \%$ ). The difference is significant at the $1 \%$ level (Wilcoxon test ${ }^{10}$ ). The variance of individual effort is 0.03 under the Fixed Wage Treatment and it rises to 0.12 under the Menu Treatment. ${ }^{11}$ Figure 2 shows that compared to a situation where all the firms pay a fixed wage (i.e. periods 1 to 8 ), the average individual effort is higher when the employees can choose between two payment schemes (i.e., periods 9 to 16$)^{12}$.

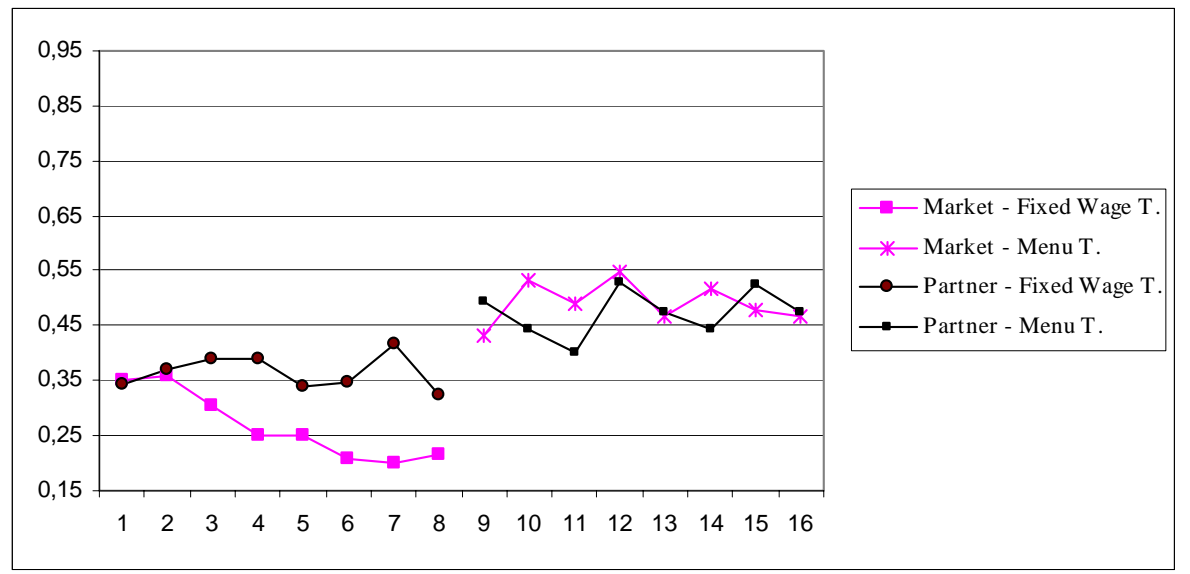

Figure 2. Evolution of average individual effort over time by treatment and condition

The model also predicts that (iii) the increases in the mean and the variance of effort can be related to both an incentive and a sorting effect, and that (iv) there is a concentration

session under the Menu Treatment.

${ }^{10}$ The non-parametric statistical analysis follows Siegel and Castellan (1988). The Wilcoxon signed-rank test is denoted as the Wilcoxon test and the Wilcoxon Mann-Whitney two sample rank-sum test as the Mann-Whitney test. The non-parametric tests as well as the econometric analysis have been made with Stata 8.0. In the partner matching protocol, each of the 24 employer-employee pairs represents one independent observation, whereas in the market protocol, each of the 6 sessions represents one independent observation.

${ }^{11}$ The same is true when we distinguish further between conditions and treatments. The variances for Fixed Wage and Menu Treatments in the market condition were 0.02 and 0.13 , respectively. Corresponding numbers for the partner condition were 0.04 and 0.09 . If the variability of individual effort is measured relative to the mean, i.e., by the coefficient of variation, the picture becomes less clear. For the market condition, the differences are unchanged: the CV is 0.09 for the Fixed Wage Treatment and 0.28 for the Menu Treatment. However, the numbers for the partner condition are 0.13 and 0.09 , respectively.

12 The increase in outcomes in period 9 seems not be a pure "restart effect" since there is a striking stability in the average level of effort throughout the second part of the experiment. We accept the null 
of high skill employees in the variable pay scheme and the low skill employees in the fixed pay scheme. Figure 3 confirms that decomposing the data by skill levels helps in understanding that the incentive property of a variable pay scheme cannot alone explain the observed increase in productivity. In each condition, the high skill and the low skill employees exert similar levels of effort when they are paid a fixed wage (MannWhitney tests). However, when the opportunity to choose the pay scheme is provided, due to a substantial increase in the productivity of the high skill employees, but not of the low skill employees, the difference in productivity by skill level increases dramatically (Mann-Whitney tests, 1\% significance for the market protocol and 5\% for the partner protocol). This is the result of the fact that considerably more high skill employees choose the variable pay than the low skill agents when this opportunity is available. In the market condition, only $14.4 \%$ of the low skill employees choose the variable pay scheme and they exert on average a low effort under both the variable pay scheme (0.29) and the fixed pay scheme (0.23); in contrast, $63 \%$ of the high skill employees choose the variable pay scheme (Mann-Whitney test, 1\% significance) and they exert either the maximum level of effort when they are paid a variable wage (0.96) or a low level of effort when paid a fixed wage (0.27). This is confirmed by regressions (1) and (2) in Table 4 below which show that the probability to choose the variable pay is higher when the employee is high skilled.

hypothesis of no significant difference in the average individual effort in period 9 and in the further 7 periods taken all together, for pooled data and data separated by condition (Wilcoxon tests). 


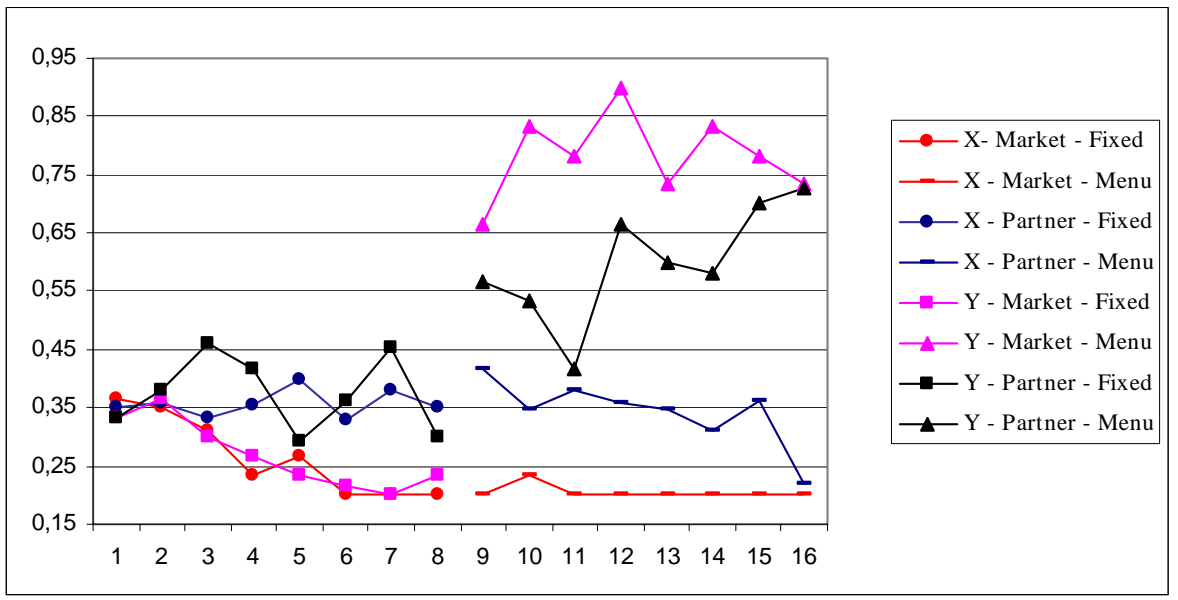

Figure 3. Evolution of average individual effort by skill,

treatment and condition

These simple observations suggest that the model delivers good predictions. However, while $88.2 \%$ of effort choices are at the equilibrium in the market condition, $43.5 \%$ of the decisions are out of the equilibrium in the partner matching condition (difference significant at the $10 \%$ level, Mann-Whitney test). The latter are made by employees who choose an effort level between the minimum effort under the fixed pay scheme and the maximum effort under the variable pay scheme (i.e., between $y_{0}$ and $y^{* *}$ in Figure 1). Are other-regarding preferences a prime candidate for explaining the departures from equilibrium?

With other-regarding preferences, the hypotheses are that $(v)$ there is a smaller increase in the average individual effort, and (vi) there is less sorting of the employees, more employees of both skill types being concentrated in the fixed pay scheme. A comparison of the market and the partner matching conditions helps in testing these hypotheses. As predicted, under the former, average individual effort increases from 0.24 under the Fixed Wage Treatment to 0.47 (+95.8\%) under the Menu Treatment (difference significant at the $5 \%$ level, Wilcoxon test). Under the latter, which is more representative of a long term employment relationship in which social preferences are 
more likely to flourish, the increase is only from 0.36 to $0.47(+30.6 \%$, difference only significant at the $10 \%$ level, Wilcoxon test). In the partner matching condition, the high skill employees still exert a very high mean effort when paid a variable wage (0.92) the incentive property of the variable wage is confirmed - but only $36.7 \%$ of them opt for this pay scheme whereas $63 \%$ of the high skill employees make the same choice in a spot market. The frequency of choices of the variable pay scheme by the high skill and the low skill employees is not significantly different (Mann-Whitney test). When the employment relationships are of long-term nature, there is less segmentation by the payment schemes in terms of skills. This differentiated sorting effect is hidden behind the ostensible similarity of the average effort under the Menu Treatment in the spot and the long-term relationships.

To explain the differences between protocols, one can put forward the hypothesis that other-regarding preferences play a decisive role both in the provision of incentives, and in the incentive and sorting effects of variable pay.

The hypothesis of the role of other-regarding preferences is addressed by considering four interacting dimensions: the firms' contractual offers, the decision of employees to accept or reject such offers, the choice of the pay scheme and the actual effort decision.

\section{B. Other-regarding preferences in the design of contractual offers}

Fairness influences the provision of incentives. Figure 4 indicates that in contrast to predictions based on selfish preferences, a relatively high proportion of the firms offer generous fixed wages, in particular when the employment relationship is long-term. This is in accordance with the existing experimental literature on the subject (Gächter and Fehr, 2001). The relative frequency of the minimum wage propositions increases slightly in the Menu Treatment under the partner matching condition (from 24\% under 
the Fixed Wage Treatment to $30.2 \%$ under the Menu Treatment). The increase is smaller in the market condition (from $44.5 \%$ to $48.9 \%$ ). These increases are never statistically significant (Wilcoxon tests).

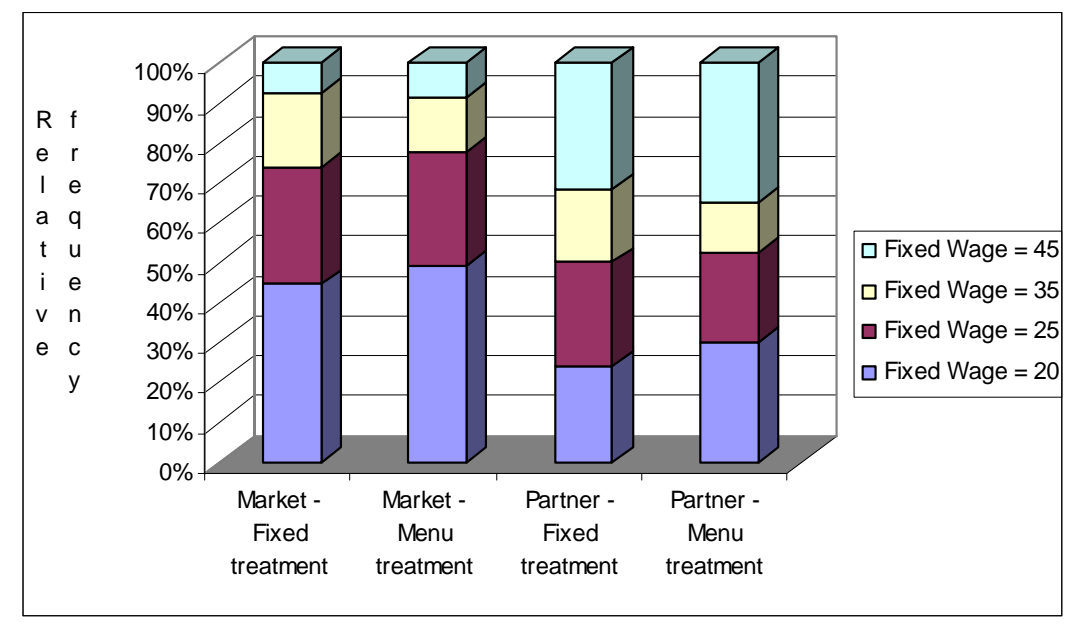

Figure 4. Distribution of fixed wage offers under various treatments and protocols

Some firms pay efficiency wages to elicit a reciprocal effort response from the employee. Overall, the correlation of fixed wage and desired effort level is positive. Spearman rank correlation coefficients yield $\rho=0.49$ in the market protocol that is not significant and $\rho=0.40$ in the partner matching condition that is significant at $10 \%$. In order to obtain a more detailed picture of the determinants of firms' choices of wage offers, we estimated a random-effects Tobit model, taking into account the left and right censoring of the data, the results of which are displayed in Table 2. We estimate two separate regressions since the Mann-Whitney test indicates a difference in the average fixed wage offers in the two conditions (10\% significance). 
Table 2. The choice of the fixed wage offers

\begin{tabular}{|l|c|c|}
\hline $\begin{array}{l}\text { Dependent variable: The firm's choice of } \\
\text { the fixed wage offer }\end{array}$ & Market & Partner \\
\hline Conditions & - & 1.542 \\
& & $(0.658)$ \\
High skill employee * Menu Treatment & $16.649 * * *$ & $42.229^{* * *}$ \\
Lagged effort under the fixed wage scheme & $(0.000)$ & $(0.000)$ \\
& 1.209 & $-7.815^{* *}$ \\
Lagged negative firm's payoff & $(0.419)$ & $(0.015)$ \\
& & -4.018 \\
Female & $-4.024^{*}$ & $(0.508)$ \\
& $(0.071)$ & $22.818^{* * *}$ \\
Constant & $19.112^{* * *}$ & $(0.000)$ \\
\hline Number of observations & $(0.000)$ & 306 \\
Wald c & 659 & 29.03 \\
Prob>c ${ }^{2}$ & 18.44 & 0.0000 \\
\hline
\end{tabular}

Note: Significance levels in parentheses.

In the market condition, the wage offer is mainly determined by the experience of positive reciprocity from the group of employees. This suggests that by paying high wages, firms try to attract reciprocal subjects more than skilled ones. Time and individual characteristics have no significant influence, except gender. In the partner matching condition, the firm rewards the reciprocity expressed in the previous period by its employee and punishes its absence ${ }^{13}$. Interestingly, knowing its employee's skill and the availability of both pay schemes does not influence the firm's wage offer. Although this alternative strategy should motivate the high skill employee to choose the variable pay and the maximum effort, most firms appear to prefer informal reciprocal interactions rather than making separating offers. This observation is consistent with Fehr and Schmidt's (2000) conclusion that firms have a strong preference for less complete contracts because of fairness concerns despite the fact that they could earn

\footnotetext{
${ }^{13}$ This can be seen from the negative sign associated with the coefficient of the "lagged negative firm's payoff" variable. The firm makes a negative payoff only when it offers a wage equal to 35 or 45 and if its employee chooses the minimum effort or an effort equal to 0.4 with the maximum wage.
} 
more under more complete contracts. A likely explanation is positive inequality aversion (Fehr and Schmidt, 1999). Next we turn to look at whether the generosity of such contractual offers influences the behavior of employees and hence, the incentive and sorting effects of the variable pay.

\section{Other-regarding preferences and the acceptance of contracts}

In theory, no contract should be rejected. In the market condition, only 5 contracts out of $760(0.7 \%)$, offering the minimum wage and demanding a level of effort $\geq 0.8$, are rejected. In the partner matching condition, more contracts are considered as being unfair: 32 contracts out of 384 are rejected (8.3\%). This represents $11.5 \%$ of the minimum wage offers and $20.4 \%$ of the wage offers equal to 25 even if in most cases the demanded effort does not exceed 0.4 . This negative reciprocity is motivated by the desire of the employee to increase the offered fixed wage. A random effects probit model, see Equation (6), including as explanatory variables the employee's skill, the interaction between a dummy variable for the Menu Treatment and the high skill level, the rent offered by the firm and individual characteristics, demonstrates that the acceptance probability increases with the generosity of the contractual offer (5\% significance). Following (Fehr et al. 1997) and others, we proxy generosity by the rent offered. This is measured as the difference between the wage offer and the opportunity cost of providing the demanded level of effort $(w-c(\tilde{e}))$.

Prob $($ acceptance of contract $)=3.516^{* * *}-0.252$ (High skill employee $)+0.334$ (Menu

Treatment $*$ High skill employee) $+0.078 * * *$ (Offered rent)

Wald $\chi^{2}: 21.15$; Prob $>c^{2}=0.000$; number of observations: 368 
Acceptance is not influenced by the employee's skill level. This is interesting since under the Menu Treatment the high skill employee may simply increase her payoff by choosing the variable pay. Instead, contract rejections show the willingness of employees to punish the firms for offering a wage that is considered as too low.

\section{Other-regarding preferences and the choice of a pay scheme}

The two main points that can be extracted from the random-effects probit model estimates in Table 3 are that the employee's skill level is the main determinant of the choice of the variable pay, and that the generosity of the firms' contractual offers also affects this choice, albeit in the opposite direction.

Table 3. The choice of a pay scheme

\begin{tabular}{|l|c|c|}
\hline $\begin{array}{l}\text { Dependent variable: Choice of the } \\
\text { variable pay scheme }\end{array}$ & \multicolumn{2}{|c|}{ Random-effects probit model } \\
\hline Conditions & Market & Partner \\
\hline High skill employee & $2.526^{* * *}$ & $\begin{array}{c}1.234^{* * *} \\
(0.000)\end{array}$ \\
& & $(0.007)$ \\
Offered rent & $-0.061^{* * *}$ & $-0.113^{* * *}$ \\
& $(0.000)$ & $(0.000)$ \\
Time trend & $-0.125^{* * *}$ & 0.059 \\
& $(0.002)$ & $(0.342)$ \\
Constant & 0.153 & -0.758 \\
& $(0.777)$ & $(0.398)$ \\
\hline Number of observations & 375 & 177 \\
Wald c & 54.78 & 29.80 \\
Prob $>c^{2}$ & 0.0000 & 0.0000 \\
\hline
\end{tabular}

Note: we only consider the observations on accepted contracts from the Menu Treatment. We included individual variables (gender, age, school, experience) in the regressions but as none of them turned out to be significant, they are omitted from these regressions.

Moreover, Figure 5 shows that the proportion of employees choosing the variable pay scheme is diminishing in the offered rent intervals. When the offered rent equals zero or is negative, half of the employees choose the variable pay scheme, but when the offer is 
generous, almost all employees opt for the fixed pay scheme which allows them both to obtain a higher payoff and to share the rent more equally with the firm. The average (expected) rent offered is higher in the partner matching condition than in the market condition (Mann-Whitney test, 5\% significance); its mean is 14.3 under this protocol and 6.9 under the market one. This may explain why a smaller proportion of high skill employees choose the variable pay scheme in the partner matching condition. If otherregarding preferences may weaken the sorting effect of variable pay, do also they impact its incentive effect?

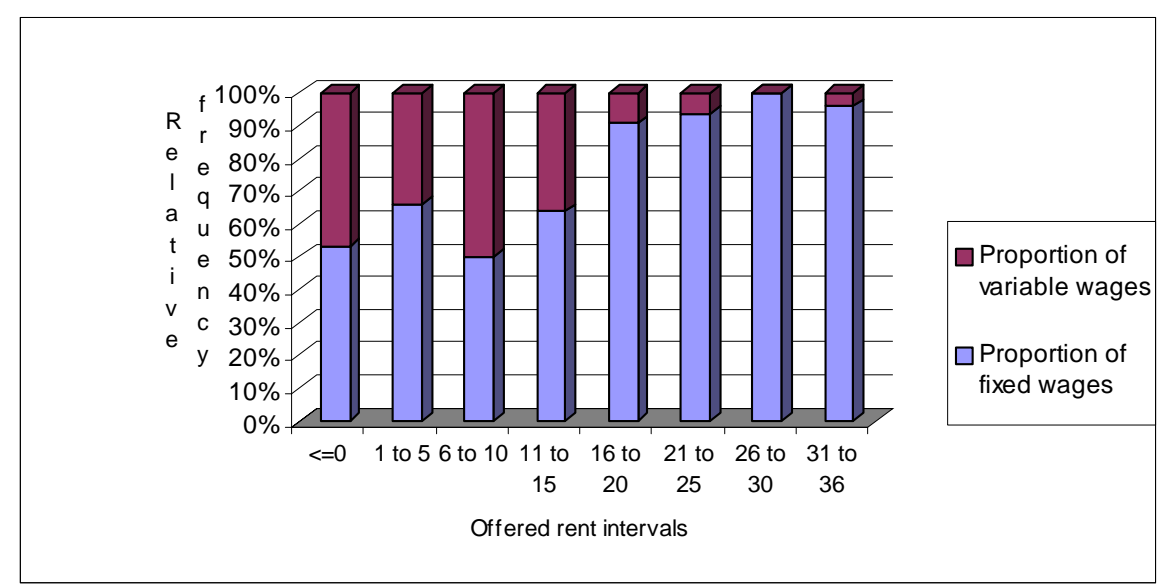

Figure.5. Relative frequency of the choice of the variable pay scheme under the Menu Treatment

\section{E. Other-regarding preferences and the choice of an effort}

We estimate a random-effects Tobit model accounting for the left and right censoring of the data to examine the determinants of the level of effort under the various pay schemes; see Table 4. Three main points emerge from the estimates. First, as predicted by theory, under the variable pay scheme, the employee's skill level is the main determinant of the actual effort level (regressions 3 and 6). Whichever condition considered, once the variable pay scheme has been chosen, the generosity of the alternative fixed wage offer has no impact on the effort decision. This suggests that the 
incentive effect of variable pay for high skill employees is inherent to the remuneration scheme itself and is not affected by other-regarding preferences.

Table 4. The choice of effort level

\begin{tabular}{|c|c|c|c|c|c|c|}
\hline Dependent variable: & \multicolumn{6}{|c|}{ Random-effects Tobit model } \\
\hline Conditions & \multicolumn{3}{|c|}{ Market condition } & \multicolumn{3}{|c|}{ Partner condition } \\
\hline $\begin{array}{l}\text { Pay schemes / } \\
\text { Treatments }\end{array}$ & $\begin{array}{c}\text { Fixed pay } \\
\text { Treatment } \\
(1) \\
\end{array}$ & $\begin{array}{c}\text { Fixed pay } \\
\text { Menu } \\
\text { Treatment } \\
(2) \\
\end{array}$ & $\begin{array}{c}\text { Variable } \\
\text { Pay - Menu } \\
\text { Treatment } \\
\text { (3) }\end{array}$ & $\begin{array}{c}\text { Fixed pay } \\
\text { Treatment } \\
\text { (4) }\end{array}$ & $\begin{array}{c}\text { Fixed pay } \\
\text { Menu } \\
\text { Treatment } \\
\text { (5) }\end{array}$ & $\begin{array}{c}\text { Variable } \\
\text { Pay - Menu } \\
\text { Treatment } \\
(6)\end{array}$ \\
\hline High skill & $\begin{array}{c}0.045 \\
(0.760)\end{array}$ & $\begin{array}{c}0.284 \\
(0.161)\end{array}$ & $\begin{array}{c}1.156^{* * *} \\
(0.000)\end{array}$ & $\begin{array}{l}-0.110 \\
(0.427)\end{array}$ & $\begin{array}{c}-0.288^{* * *} \\
(0.000)\end{array}$ & $\begin{array}{l}1.102 * * * \\
(0.000)\end{array}$ \\
\hline Offered rent & $\begin{array}{c}0.002 \\
(0.759)\end{array}$ & $\begin{array}{c}0.005 \\
(0.438)\end{array}$ & $\begin{array}{c}0.003 \\
(0.586)\end{array}$ & $\begin{array}{c}0.014^{* * * *} \\
(0.008)\end{array}$ & $\begin{array}{c}0.017 * * * \\
(0.000)\end{array}$ & $\begin{array}{c}0.001 \\
(0.826)\end{array}$ \\
\hline Time trend & $\begin{array}{c}-0.132 * * * \\
(0.000)\end{array}$ & $\begin{array}{c}-0.096 * * * \\
(0.000)\end{array}$ & $\begin{array}{c}0.017 \\
(0.408)\end{array}$ & $\begin{array}{l}-0.015 \\
(0.397)\end{array}$ & - & $\begin{array}{l}0.062 * * \\
(0.018)\end{array}$ \\
\hline Constant & $\begin{array}{l}-0.221 \\
(0.301)\end{array}$ & $\begin{array}{c}0.496 \\
(0.107)\end{array}$ & $\begin{array}{c}0.116 \\
(0.639)\end{array}$ & $\begin{array}{c}0.146 \\
(0.284)\end{array}$ & $\begin{array}{c}0.205^{* * *} \\
(0.001)\end{array}$ & $\begin{array}{l}-0.652^{*} \\
(0.077)\end{array}$ \\
\hline $\begin{array}{l}\text { Number of } \\
\text { observations } \\
\text { Wald } c^{2} \\
\text { Prob }>c^{2}\end{array}$ & $\begin{array}{c}384 \\
30.18 \\
0.000\end{array}$ & $\begin{array}{c}230 \\
14.76 \\
0.002\end{array}$ & $\begin{array}{c}145 \\
51.37 \\
0.000\end{array}$ & $\begin{array}{c}192 \\
7.35 \\
0.062\end{array}$ & $\begin{array}{c}128 \\
27.98 \\
0.000\end{array}$ & $\begin{array}{c}49 \\
62.03 \\
0.000\end{array}$ \\
\hline
\end{tabular}

Second, when the employees in the market condition are paid a fixed wage, either by choice or not, the generosity of the contract has no significant effect and effort declines over time (regressions 1 and 2). No other-regarding preferences compensate for the inherent lack of an incentive effect of the fixed wage scheme ${ }^{14}$. Despite their low cost of effort, the high skill employees do not work harder than the low skill ones. Third, when the employees in the partner matching condition are paid a fixed wage, the effort level is significantly increased in response to the offered rent and it is stable over time

\footnotetext{
${ }^{14}$ It should be noted that overall we observe less reciprocity in our posted bid market condition than in one-shot gift-exchange experiments such as Fehr et al. (1993). This is reminiscent of the results found by Charness et al. (2001) that in such a game, there is less reciprocity when, as in our experiment, the subjects are provided a comprehensive payoff table that relates wages and effort levels to both employer's and employee's payoffs.
} 
(regressions 4 and 5). The presence of other-regarding preferences in the long-term relationship, that is, the employees' reciprocity, sustains the incentive effect of the offer by the firms of a fixed wage above the equilibrium, especially for the high cost employees.

Taken together, the four elements discussed above imply that the sorting effect of the variable pay scheme in terms of skills is weaker in a long term relationship whereas its incentive effect is not affected. It should be noted that reciprocating to a generous fixed wage by a non-minimum effort instead of choosing the variable pay scheme makes the high skill employee better off than exerting the maximum effort under the variable pay scheme. It increases her payoff while reducing negative inequality aversion since it allows for a more equal rent sharing with the firm. When the fixed pay scheme is used, the observed average net payoffs are 16.9 for a low skill employee, 19.8 for a high skill employee and 19.4 for the firm. In the partner condition, when the fixed pay scheme is chosen by the employee, there is no significant difference between the firm's and the employee's payoffs, whatever her skill level (Wilcoxon tests). In contrast, choosing a variable pay scheme substantially increases inequality: the respective average payoffs become 9.7, 23.9 and 45.7. Irrespective of the condition and the employee's skill, the difference between the employee's and the firm's payoffs is always significant at the 5\% level (Wilcoxon tests).

When the firm offers the maximum wage the average net payoff of a high skill employee amounts to 33.2 under the fixed pay scheme, whereas the corresponding payoff under variable pay is 25 . This means that some firms may accept not to obtain their maximum payoff when making non-separating offers. When offering the maximum wage, the firm's average net payoff amounts to 29.4 in the partner matching 
condition while it could reach 55 if the high skill employee chooses the variable pay. One interpretation is that these firms are positively inequality averse. There are two prerequisites for these strategies to be successful: the firm is trustful and the employee makes a non-minimum effort in exchange for a high fixed wage. The two prerequisites are more easily fulfilled in the partner matching condition. But it should not be forgotten that when both schemes are available in the long term relationship, the average effort of the high skill employees is lower. This result is in accordance with findings of Shearer (2004), who emphasizes that efficiency wages that produce the same incentive effect as piece-rates are associated with higher unit costs.

\section{Discussion and Conclusion}

Economic theory of performance pay schemes predicts that the switch from a fixed pay scheme to a variable pay scheme should increase the average output per worker because of incentive effects. Moreover, if workers differ with respect to ability, the low skill employees are predicted to be indifferent between being paid a fixed pay or a performance pay with a minimum wage guarantee, whereas the high skill employees should be attracted by the performance pay since it allows them to receive a higher wage by exerting more effort. Thus, one should distinguish between the incentive and the sorting effect of a payment scheme. However, if the firm pays a high fixed wage, the attraction of the variable pay may be weaker. Behavioral motivations may play a role in the determination of the fixed pay and consequently, also in the employee's choice of pay scheme and effort level. In order to test both the model and these behavioral assumptions, we have designed a laboratory experiment in which the employers choose the level of a fixed wage and the employees can choose between two modes of payment and decide on their actual level of effort. It allows us to assess the incentive and the 
sorting effects of the variable pay scheme relative to a fixed wage and their sensitivity to other-regarding preferences such as fairness, reciprocity and inequality aversion.

Our experimental evidence confirms that a switch from a homogenous environment where all firms pay fixed wages to an environment in which both a fixed and a variable pay schemes coexist, entails an increase in both average output and the variance of individual output. Effort only increases for the high skill employees because the variable pay scheme induces them to work harder and to earn more money. The low skill employees are indifferent between the fixed and the variable pay schemes if they are offered a low wage. As a consequence, productivity depends on the skill of the employees under the variable pay scheme but not under the fixed pay scheme. This observation suggests a limit in the adoption of performance-pay despite its incentive effect. The increase in the difference in performance and pay levels between employees within a firm may be an obstacle to cooperation. The introduction of a variable pay scheme increases team heterogeneity, which usually is difficult to manage. In addition, the widening wage gap may generate envy, jealousy and conflicts. This kind of variable pay schemes is thus less likely to be implemented in firms promoting teamwork.

A comparison of the posted bid market and the partner matching conditions, reveals interesting phenomena. It shows that the employees who choose the variable pay scheme are not necessarily the most ambitious ones. Provided the rent offered is high enough, in a long-term employee-firm relationship with reciprocity and inequality aversion concerns from both sides, a non-negligible fraction of the high skill employees also opt for a fixed pay scheme. This indicates that if a firm pays efficiency wages, then the overall incentive effect of variable pay scheme is reduced because it becomes less attractive to the employees relative to the fixed pay scheme. Thus, other-regarding 
preferences of some of the subjects influence not only the provision of incentives, but also their incentive and sorting effects. It suggests that another type of sorting of the employees may operate, depending on their degree of reciprocity and not only on their ability. This could motivate the introduction of double screening model for the study of the impact of payment schemes on the labor market.

It should be noted, of course, that the current paper considers two extremes: a fully fledged spot market and a long-term worker-firm match. Introducing the possibility of a breach of the contract or a shortage of jobs on the market would constitute interesting extensions of this analysis. Other extensions are the introduction of imperfections in the output measurement or uncertainty in the environment. However, although one should be cautious before extrapolating the current experimental results into a real work setting, fairness, reciprocity and inequality aversion in longer-term employment relationships could explain why we observe less segmentation of labour markets according to ability and mode of payment than expected by theory. The results suggest that we would expect to observe less performance pay in longer term employment relationships. ${ }^{15}$ This, in turn, could imply that differences across countries with respect to the length of employment relations, due to e.g., employment protection legislation, may be accompanied by differences in the prevalence of performance pay schemes.

\footnotetext{
${ }^{15}$ Goldin (1986) makes a related argument for industry differences in piece rates. She uses historical data to show that industries employing relatively many female workers used piece rates to a higher extent than male-dominated industries. The interpretation is that males are motivated by internal labor market career incentives, whereas the women, who had much shorter employment spells, had to be motivated by other more short-term incentives.
} 


\section{Appendix. Instructions for the Fixed Wage Treatment and the Menu Treatment in the posted bid market condition ${ }^{16}$}

You are about to partake in an experiment on decision-making organized for the CNRS (Centre National de la Recherche Scientifique) and the Aarhus School of Business in Denmark. During this session, you can earn money. The amount of your earnings depends not only on your decisions, but also on the decisions of the other participants you will interact with. During the session, your earnings will be calculated in points,

$$
\text { with } 100 \text { points }=4 \text { Euros }
$$

At the end of the session, all the profits you have made in each period will be added up and converted into Euros. In addition, you will receive a show-up fee of 4 Euros. Your earnings will be paid to you in cash in a separate room in order to preserve confidentiality.

During this session, 8 buyers interact with 8 sellers. There are two categories of sellers ( $4 \mathrm{X}$ sellers and 4 Y sellers), characterized by different costs. You will be assigned one of these roles (either as a buyer, as a $\mathrm{X}$ seller, or as a Y seller) at random at the beginning of the experiment. You will keep the same role throughout the session. You will never be informed of the identity of the participants you will interact with.

The session consists of two parts. The instructions for the second part will be distributed at the end of the first one.

\section{The decision-making in each period of the first part}

The first part consists of 8 periods. During each period, a good is traded on the market. Each period consists of two stages.

In the first stage, each buyer has to make an offer for trading one unit of the good. The offer consists of both:

․ the price he accepts to pay immediately for buying one unit of the good among four possible prices (20, 25, 35 and 45), and

- the desired level of quality for this good among five possible qualities $(0.2,0.4,0.6,0.8$, and 1$)$.

A buyer can make only one offer and he can buy only one unit of the good in each period.

Once all the buyers have determined their offers, the 8 offers are displayed at the same time on the sellers' screens. Each seller will then one by one be able to choose one and only one offer, when invited to proceed by the appearance of a green mark on his screen. The order in which each seller can choose an offer among the remaining offers is random. As soon as an offer has been accepted, it is removed from the screens of the sellers. A seller can decide not to accept any offer.

As soon as a buyer's offer has been accepted, this buyer pays the price to his seller and they proceed immediately to the second stage.

In the second stage, once he has been paid the price by the buyer, it is up to the seller to choose the quality of the good he actually delivers to this buyer, among the values: $0.2,0.4,0.6,0.8$, and 1 .

Each buyer is then informed on the acceptance of his offer, on the type, X or Y, of his seller, on the actual quality of the good and on his payoff for the current period. The seller is also informed about his payoff.

Then a new period starts automatically. New offers are made. The order of presentation of these offers is randomly determined, so that, for example, the first offer which is displayed on the screen does not always come from the same buyer. The probability to interact with the same participant in two consecutive periods is thus low.

\footnotetext{
${ }^{16}$ The other set of instructions is available upon request to the authors.
} 


\section{How are the payoffs in each period determined?}

\section{The seller's payoff}

If the seller has not accepted any offer, his payoff is zero for the period.

If the seller has accepted an offer, he must subtract two costs from the price he received:

o a production cost, amounting to 8 points

o a quality cost associated with the level of quality he has chosen according to the table below

\begin{tabular}{|l|c|c|c|c|c|}
\hline Quality levels & 0.2 & 0.4 & 0.6 & 0.8 & 1 \\
\hline Quality costs for the X sellers & 2 & 6 & 12 & 20 & 30 \\
\hline Quality costs for the Y sellers & 1 & 3 & 5 & 8 & 12 \\
\hline
\end{tabular}

The higher is the number chosen by the seller, the higher is the level of quality. The higher the quality level, the higher the cost to the seller.

The seller's payoff in points is thus determined by the computer by the following formula:

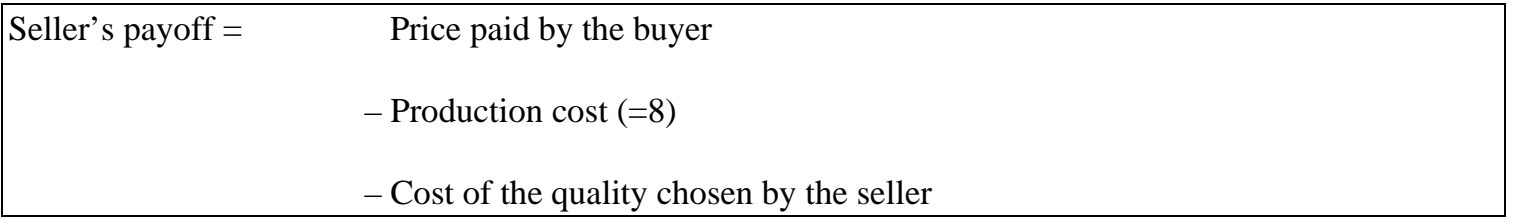

\section{The buyer's payoff}

If the buyer's offer has not been accepted, his payoff is zero for the period.

If his offer has been accepted, the buyer gets a certain amount of points (reselling price) from the experimentalist for the good he bought. This reselling price is 100 points.

From this reselling price, the buyer must subtract the price paid to the seller. To determine the buyer's payoff, this amount is then multiplied by the quality level actually chosen by the seller.

The buyer's payoff in points is thus determined by the computer by the following formula:

$$
\begin{aligned}
& \text { Buyer's payoff }=\quad \begin{array}{l}
\text { (Reselling price }- \text { Price paid to the seller) } \\
\text { x Quality chosen by the seller }
\end{array}
\end{aligned}
$$

On the other form which has been distributed, Table A displays all the payoffs in points associated with all possible decisions. Rows represent the various possible prices. Columns represent the various possible actual quality levels.

Within each cell at the crossing of one price and one actual quality, you can observe three values. The upper category (blue) corresponds to the X seller's payoff. The medium category (yellow) corresponds to the Y seller's payoff. The last category (pink) indicates the buyer's payoff.

These payoffs are net payoffs, after deduction of the production and quality costs for the seller and after taking the reselling price into account and after deduction of the price for the buyer. 


\section{Further information}

Before starting the session, we will ask you to answer some questions about these instructions. As soon as you have answered these questions correctly, you will been kindly requested to enter personal information about your gender, your age, your school, your level and field of studies, your situation in the labor market, and whether you already earlier participated in an experiment. These pieces of information will remain confidential. Then, the experiment will start.

If you have any questions regarding these instructions, please raise your hand; your question will be answered in private. Throughout the entire session, talking is not allowed. Any violation of this rule will result in being excluded from the session and not receiving payment.

Thank you for your participation. 
Table A. Net payoffs of the buyers and the sellers

\begin{tabular}{|c|c|c|c|c|c|c|}
\hline Actual quality & & & & & & \\
\hline $\begin{array}{l}\text { Price chosen by the } \\
\text { paid by the seller } \\
\text { buyer }\end{array}$ & 0.2 & 0.4 & 0.6 & 0.8 & 1 & $\begin{array}{c}\text { Net } \\
\text { Payoff }\end{array}$ \\
\hline & 10 & 6 & $\mathbf{0}$ & -8 & -18 & $\mathrm{X}$ seller \\
\hline 20 & 11 & 9 & 7 & 4 & $\mathbf{0}$ & Y seller \\
\hline & 16 & 32 & 48 & 64 & 80 & Buyer \\
\hline & 15 & 11 & 5 & -3 & -13 & $\mathrm{X}$ seller \\
\hline 25 & 16 & 14 & 12 & 9 & 5 & Y seller \\
\hline & 15 & 30 & 45 & 60 & 75 & Buyer \\
\hline & 25 & 21 & 15 & 7 & -3 & $\mathrm{X}$ seller \\
\hline 35 & 26 & 24 & 22 & 19 & 15 & Y seller \\
\hline & 13 & 26 & 39 & 52 & 65 & Buyer \\
\hline & 35 & 31 & 25 & 17 & 7 & $\mathrm{X}$ seller \\
\hline 45 & 36 & 34 & 32 & 29 & 25 & Y seller \\
\hline & 11 & 22 & 33 & 44 & 55 & Buyer \\
\hline
\end{tabular}

Reminder: the buyer chooses a price and a desired quality; then the seller chooses the actual quality

Within each cell at the crossing of one price and one actual quality, you can observe three values. The upper category (blue) corresponds to the X seller's payoff. The medium category (yellow) corresponds to the Y seller's payoff. The last category (pink) indicates the buyer's payoff.

These payoffs are net payoffs, after deduction of the production and quality costs for the seller and after taking the reselling price into account and after deduction of the price for the buyer. 


\section{Instructions for the second part}

This second part consists also of 8 periods.

\section{What is new compared to the first Part? \\ First stage}

Each buyer has to make an offer that from now on consists of two possible modes of payment in exchange for one unit of the good, the Mode of Payment A and the Mode of Payment B. If this offer is accepted by a seller, this later will opt for one of these two modes.

- Within the "Mode of Payment A": the buyer chooses

a the price he accepts to pay immediately for buying one unit of the good among four possible prices (20, 25, 35 and 45) and

a the desired level of quality for this good among five possible qualities $(0.2,0.4,0.6,0.8$, and 1).

This price is paid as soon as a seller has accepted the offer and chosen this mode of payment. This mode of payment corresponds to the conditions in use in the first part of the session.

- Within the "Mode of Payment B": the price which will apply is determined by a price schedule depending on the actual quality chosen by the seller who will have accepted the offer and this mode of payment, as indicated in the table below. Each price is here equal to:

(50 times the corresponding quality level) - 5

with a minimum price of 20 and a maximum price of 45 . Under this Mode, the price is thus paid after the seller has chosen the actual quality level of the good. This price schedule is the same for all the buyers.

\section{Mode of Payment B}

\begin{tabular}{|l|c|c|c|c|c|}
\hline Quality chosen by the seller & 0.2 & 0.4 & 0.6 & 0.8 & 1 \\
\hline $\begin{array}{l}\text { Price paid by the buyer after the choice of the } \\
\text { quality by the seller }\end{array}$ & 20 & 20 & 25 & 35 & 45 \\
\hline
\end{tabular}

This table should be read as follows: for example, if the seller chooses the quality 0.2 , then the buyer will pay the price 20 ; if the seller chooses the quality 0.6 , the buyer will pay the price 25 ; and so on.

Once the buyers have determined their offers within the two Modes of payment, the 8 offers are displayed on the sellers' screens at the same time. Each seller will then one by one be able to choose one offer.

As soon as he has accepted a buyer's offer, the seller chooses one of the two Modes of Payment proposed by this buyer, either Mode A or Mode B, and both proceed immediately to the second stage.

\section{Second stage}

- If the seller has accepted the offer of a buyer and chosen the Mode of Payment A: after having been paid the price by the buyer, the seller chooses the quality of the good that he delivers to the buyer among the values: $0.2,0.4,0.6,0.8$ or 1 .

- If the seller has accepted the offer of a buyer and chosen the Mode of Payment B: the seller chooses the quality of the good that he delivers to the buyer and then, the price is paid by the buyer according to the price schedule.

All the other conditions in use in the first part continue to apply. The information feedback is the same as in the first part but in addition, the buyer is informed about the choice of the Mode of payment by his seller. The payoffs are determined in the same way as in the first part of the session.

Reminder: the seller's payoff in points is given by the following formula: 


\begin{tabular}{|l|l|}
\hline Seller's payoff $=$ & Price paid by the buyer \\
& Production cost $(=8)$ \\
& - Cost of the quality chosen by the seller \\
\hline
\end{tabular}

Reminder: the buyer's payoff in points is given by the following formula:

\author{
Buyer's payoff $=\quad($ Reselling price - Price paid to the seller $)$ \\ x Quality chosen by the seller
}

The difference relative to the first part is that the price is determined according either to the Mode of Payment A or to the Mode of payment B, as chosen by the seller.

The attached sheet of paper presents two tables displaying all the payoffs in points associated with all possible decisions under each mode of payment. Table $\mathrm{A}$ is the same as the one used in the first part and corresponds to Mode of Payment A. Table B corresponds to Mode of Payment B. These payoffs are still net payoffs.

You are not allowed to ask questions about this set of instructions. So please read them carefully and fill out the attached questionnaire. After your answers have been checked, we will restart the session. 


\section{Net payoffs of the buyers and the sellers}

Table A. Mode of Payment A

\begin{tabular}{|c|c|c|c|c|c|c|}
\hline $\begin{array}{l}\text { Actual Quality } \\
\text { Price }\end{array}$ & 0.2 & 0.4 & 0.6 & 0.8 & 1 & $\begin{array}{c}\text { Net } \\
\text { Payoffs }\end{array}$ \\
\hline \multirow{3}{*}{20} & 10 & 6 & 0 & -8 & -18 & X seller \\
\hline & 11 & 9 & 7 & 4 & 0 & Y seller \\
\hline & 16 & 32 & 48 & 64 & 80 & Buyer \\
\hline \multirow{3}{*}{25} & 15 & 11 & 5 & -3 & -13 & $\mathrm{X}$ seller \\
\hline & 16 & 14 & 12 & 9 & 5 & Y seller \\
\hline & 15 & 30 & 45 & 60 & 75 & Buyer \\
\hline \multirow{3}{*}{35} & 25 & 21 & 15 & 7 & -3 & X seller \\
\hline & 26 & 24 & 22 & 19 & 15 & Y seller \\
\hline & 13 & 26 & 39 & 52 & 65 & Buyer \\
\hline \multirow{3}{*}{45} & 35 & 31 & 25 & 17 & 7 & $\mathrm{X}$ seller \\
\hline & 36 & 34 & 32 & 29 & 25 & Y seller \\
\hline & 11 & 22 & 33 & 44 & 55 & Buyer \\
\hline
\end{tabular}

Mode A: the buyer chooses a price and a desired quality Then the seller chooses the actual quality.
Table B. Mode of Payment B

\begin{tabular}{|l|c|c|c|c|c|}
\hline Actual Quality & 0.2 & $\mathbf{0 . 4}$ & $\mathbf{0 . 6}$ & $\mathbf{0 . 8}$ & $\mathbf{1}$ \\
\hline Prix & 20 & 20 & 25 & 35 & 45 \\
\hline X seller's net payoff & 10 & 6 & 5 & 7 & 7 \\
Y seller's net payoff & 11 & 9 & 12 & 19 & 25 \\
Buyer's net payoff & 16 & 32 & 45 & 52 & 55 \\
\hline
\end{tabular}

Mode B: the seller chooses an actual quality Then the corresponding price applies according to the price schedule.

In each cell at the crossing of a price and a quality, the upper category (blue) corresponds to the X seller's payoff. The medium category (yellow) corresponds to the Y seller's payoff and the third category (pink) indicates the buyer's payoff.

These payoffs are net payoffs, after deduction of the production and quality costs for the seller and after taking the reselling price into account and after deduction of the price for the buyer. 


\section{References}

Baker, G.P., R. Gibbons and K.J. Murphy (1994). "Subjective Performance Measures in Optimal Incentive Contracts.” Quarterly Journal of Economics 109: 1125-1156

Barro, J. and N. D. Beaulieu (2003). Selection and Improvement. Physician Responses to Financial Incentives. Manuscript, Harvard Business School.

Bertrand, M. (forthcoming). "From the Invisible Handshake to the Invisible Hand? How Import Competition Changes the Employment Relationship." Journal of Labor Economics

Bohnet, I. and F. Oberholzer-Gee (2002)." Pay for Performance: Motivation and Selection Effects." In: B. S. Frey and M. Osterloh. (eds.): Successful Management by Motivation. Berlin, Springer.

Booth, A. and J. Frank (1999). "Earnings, Productivity, and Performance-Related Pay." Journal of Labor Economics 17(3): 447-463.

Charness, G., Frechette, G., Kagel, J. (2001). "How Robust is Laboratory Gift Exchange?”, Working Paper http://ssrn.com/abstract=292854.

Falk, A., S. Gächter and J. Kovács (1999). "Intrinsic motivation and extrinsic incentives in a repeated game with incomplete contracts." Journal of Economic Psychology 20: 251-284.

Fehr, E. and S. Gächter (2002). "Do incentive contracts crowd-out voluntary cooperation?" University of Zurich Working Paper.

Fehr, E., S. Gächter and G. Kirchsteiger (1997). "Reciprocity as a Contract Enforcement Device: Experimental Evidence." Econometrica 65(4): 833-860.

Fehr, E., G. Kirchsteiger and A. Riedl (1993). "Does Fairness Prevent Market Clearing? An Experimental Investigation." Quarterly Journal of Economics 108: 437-459.

Fehr, E., G. Kirchsteiger and A. Riedl (1996). "Involuntary Unemployment and NonCompensating Wage Differentials in an Experimental Labour Market." Economic Journal 106: 106-121.

Fehr, E., G. Kirchsteiger and A. Riedl (1998). "Gift exchange and reciprocity in competitive experimental markets." European Economic Review 42: 1-34.1-27

Fehr, E. and K. M. Schmidt (1999). "A Theory of Fairness, Competition and Cooperation." Quarterly Journal of Economics 114: 817-868.

Fehr, E. and K. M. Schmidt (2000). "Fairness, incentives, and contractual choices." European Economic Review 44: 1057-1068. 
Freeman, R. B. and M. M. Kleiner (1998). "The Last American Shoe Manufacturers: Changing the Method of Pay to Survive the Foreign Competition." NBER Working Paper 6750.

Goldin, C. (1986). "Monitoring Costs and Occupatioonal Segregation by Sex: A Historical Analysis." Journal of Labor Economics 4: 1-27

Gächter, S. and A. Falk (2002). Work Motivation, Institutions, and Performance. Experimental Business Research. R. Zwick and A. Rapoport. Boston, Kluwer Academic Publishers: 351-372.

Gächter, S. and E. Fehr (2001). Fairness in the Labour Market - A Survey of Experimental Results. Surveys in Experimental Economics, Bargaining, Cooperation and Election Stock Markets. F. Bolle and M. LehmannWaffenschmidt. Berlin, Physica Verlag.

Lazear, E.P. (1986). "Salaries and Piece Rates." Journal of Business 59: 405-431

Lazear, E. P. (1999). "Output-based Pay: Incentives or Sorting?" NBER Working Paper Series 7419.

Lazear, E. P. (2000). "Performance Pay and Productivity." American Economic Review 90: 1346-1361.

MacLeod, W.B. and D. Parent (1999). "Job Characteristics and the Form Of Compensation". Research in Labor Economics, Volume 18, 177-242

MacLeod, W.B. and J.M. Malcomson (1989). "Implicit Contracts, Incentive Compatibility, and Involuntary Unemployment". Econometrica 57: 447-480

Malcomson, J.M. (1999). "Individual Employment Contracts". In: O.C. Ashenfelter and D. Card (eds.), Handbook of Labor Economics, Volume 3B. Amsterdam, NorthHolland

Nagin, D. S., J. B. Rebitzer, S. Sanders and L.J. Taylor (2002). "Monitoring, Motivation, and Management: The Determinants of Opportunistic Behavior in a Field Experiment." American Economic Review 92: 850-873.

Parent, D. (1997). "Methods of Pay and Earnings: A Longitudinal Analysis." CIRANO Working Paper 97s-14.

Paarsch, H. and B. Shearer (1999). "The Response of Worker Effort to Piece Rates: Evidence from the British Columbia Tree-Planting Industry." Journal of Human Resources 34: 643-667

Shearer, B. (2004). "Piece Rates, Fixed Wages and Incentives: Evidence from a Field Experiment." Review of Economic Studies 71 (2): 513-534. 
Siegel, S. and Castellan, N. J. (1988). Nonparametric Statistics for the Behavioral Sciences. Boston: McGraw-Hill, 1988.

Zeiliger, R. (2000). A presentation of Regate, Internet Based Software for Experimental Economics. http://www.gate.cnrs.fr/ zeiliger/regate/RegateIntro.ppt, GATE. 